\title{
Preparation of Compact Agarose Cell Blocks from the Residues of Liquid-Based Cytology Samples
}

\author{
Suk Jin Choi • Yeon Il Choi \\ Lucia Kim • In Suh Park \\ Jee Young Han · Joon Mee Kim \\ Young Chae Chu \\ Department of Pathology, Inha University \\ Hospital, Inha University School of Medicine, \\ Incheon, Korea
}

\section{Received: August 13, 2014 \\ Revised: September 12, 2014 \\ Accepted: September 16, 2014}

\section{Corresponding Author}

Suk Jin Choi, M.D.

Department of Pathology, Inha University Hospital,

Inha University School of Medicine, 27 Inhang-ro,

Jung-gu, Incheon 400-711, Korea

Tel: $+82-32-890-3980$

Fax: $+82-32-890-3464$

E-mail: 204058@inha.ac.kr
Background: Inevitable loss of diagnostic material should be minimized during cell block preparation. We introduce a modified agarose cell block technique that enables the synthesis of compact cell blocks by using the entirety of a cell pellet without the loss of diagnostic material during cell block preparations. The feasibility of this technique is illustrated by high-throughput immunocytochemistry using high-density cell block microarray (CMA). Methods: The cell pellets of SurePath residues were pre-embedded in ultra-low gelling temperature agarose gel and re-embedded in standard agarose gel. They were fixed, processed, and embedded in paraffin using the same method as tissue sample processing. The resulting agarose cell blocks were trimmed and represented on a CMA for high-throughput analysis using immunocytochemical staining. Results: The SurePath residues were effectively and entirely incorporated into compact agarose cell buttons and embedded in paraffin. Sections of the agarose cell blocks revealed cellularities that correlated well with corresponding SurePath smears and had immunocytochemical features that were sufficient for diagnosis of difficult cases. Conclusions: This agarose-based compact cell block technique enables preparation of high-quality cell blocks by using up the residual SurePath samples without loss of diagnostic material during cell block preparation.

Key Words: Immunocytochemistry; Biopsy, fine-needle; Paraffin embedding; Sepharose; Cell block microarray
The cell block technique is an important complement to current methods for cytologic diagnosis of cytologic samples. The cell block can retain minute tissue fragments equivalent to microbiopsy, providing architectural insight as well as cytomorphologic details. ${ }^{1}$ Compared to cytologic smears, cell block sections are preferred for immunocytochemistry with panels of antibodies to increase diagnostic accuracy of difficult cases because the quality of immunostaining of the cell block sections is identical to that of formalin-fixed paraffin embedded tissue (FFPET) samples. ${ }^{2-5}$

In conventional simple sedimentation methods, the cytology sample is centrifuged and the cell pellets are processed and impregnated with paraffin. ${ }^{6}$ Before being subjected to routine tissue processing sequences, the cell pellets are transferred to lens paper usually with a sharp wood dipstick or a metal spatula. However, this method can cause significant loss or dilution of cells, resulting in severe scarcity of cellularity in the cell block sections. ${ }^{3,7}$ This is the case especially when the cell blocks are prepared from samples with low cellularity such as residues of liquid-based cytology (LBC) cytologic samples in which the quantity of residual informative cells is usually small.

An alternative method using intermediate embedding medium for cell block preparation was introduced in 1986 by Olson et $a l^{8}$ Instead of wrapping the cell pellet with lens paper, they used melted bacterial agar as an intermediate embedding medium to resuspend the cell pellet. Kerstens et al. ${ }^{9}$ improved this technique in terms of cellularity yield by using melted agarose to resuspend the cell pellet. Even though the diagnostic utility of agarose-based cell block preparation was further validated by additional studies, ${ }^{10-12}$ the conventional agarose cell block technique does not seem to be commonly used in routine cytopathology practice, which is likely due to several drawbacks.

The major drawback of using the conventional agarose cell block technique is that the agarose solution should be kept warm (usually $>50-60^{\circ} \mathrm{C}$ ) to prevent premature solidification of the standard agarose gel while the cell pellet is resuspended. If the agarose solution cools, the cell pellet cannot be homogeneously resuspended in the agarose solution at room temperature, re- 
sulting in uneven distribution of diagnostically important elements in the cell block sections. Although these problems can be overcome by using commercial kits or automated machines, ${ }^{13,14}$ many cytopathologists at institutions with limited resources cannot afford these commercial devices. Furthermore, the quality of cell blocks is not always satisfactory even such sophisticated tools. ${ }^{15}$

Herein, we illustrate a modified agarose cell block method to obtain compact cell blocks of high-quality from residues of the LBC samples. The feasibility of this technique is demonstrated by construction of a cell block microarray (CMA) and high-throughput immunocytochemistry.

\section{MATERIALS AND METHODS}

The schematic flow chart of the protocol is represented in Fig. 1.

\section{Preparation of resuspending medium and re-embedding medium}

An ultra-low gelling temperature (ULGT) agarose (Agarose Type IX-A, Sigma-Aldrich, St. Louis, MO, USA) that gels at temperature $<17^{\circ} \mathrm{C}$ was used as a resuspending medium. A standard agarose (Agarose Type I-A, Sigma-Aldrich) that gels at $<36^{\circ} \mathrm{C}$ was used as a re-embedding medium. Each agarose material was melted in boiling water at $3 \%(\mathrm{w} / \mathrm{v})$. In order to preserve gelation quality of the agarose solutions, they were kept at $4^{\circ} \mathrm{C}$ with the cap fully tightened. When ready to be used, they were re-melted using a microwave oven. The re-melted ULGT agarose solution was then kept at room temperature while the re-melted standard agarose solution was kept in the oven set at $60^{\circ} \mathrm{C}$ to prevent premature solidification prior to use.

\section{Preparation of compact cell buttons}

We recruited consecutive 37 cytology case samples to be included in this study. There were cases that were from residual LBC samples after rendering the cytodiagnosis based on SurePath smears (SurePath, TriPath Care Technologies, Burlington, NC, USA), including 30 ultrasound-guided thyroid fine needle aspirates (FNAs), two lymph node FNAs and five serous effusions. Each SurePath residue was subjected to centrifugation and the cell pellet was resuspended in 200-300 $\mu \mathrm{L}$ buffered formalin. After incubation for 1 hour at room temperature, the suspension was entirely transferred to a $1.5 \mathrm{~mL}$ Eppendorf reaction tube and was centrifuged on a table-top centrifuge for 30 seconds at 15,000 rpm (Fig. 2A). Then, the supernatant was carefully discarded by pipetting, leaving a formalin-fixed cell pellet.

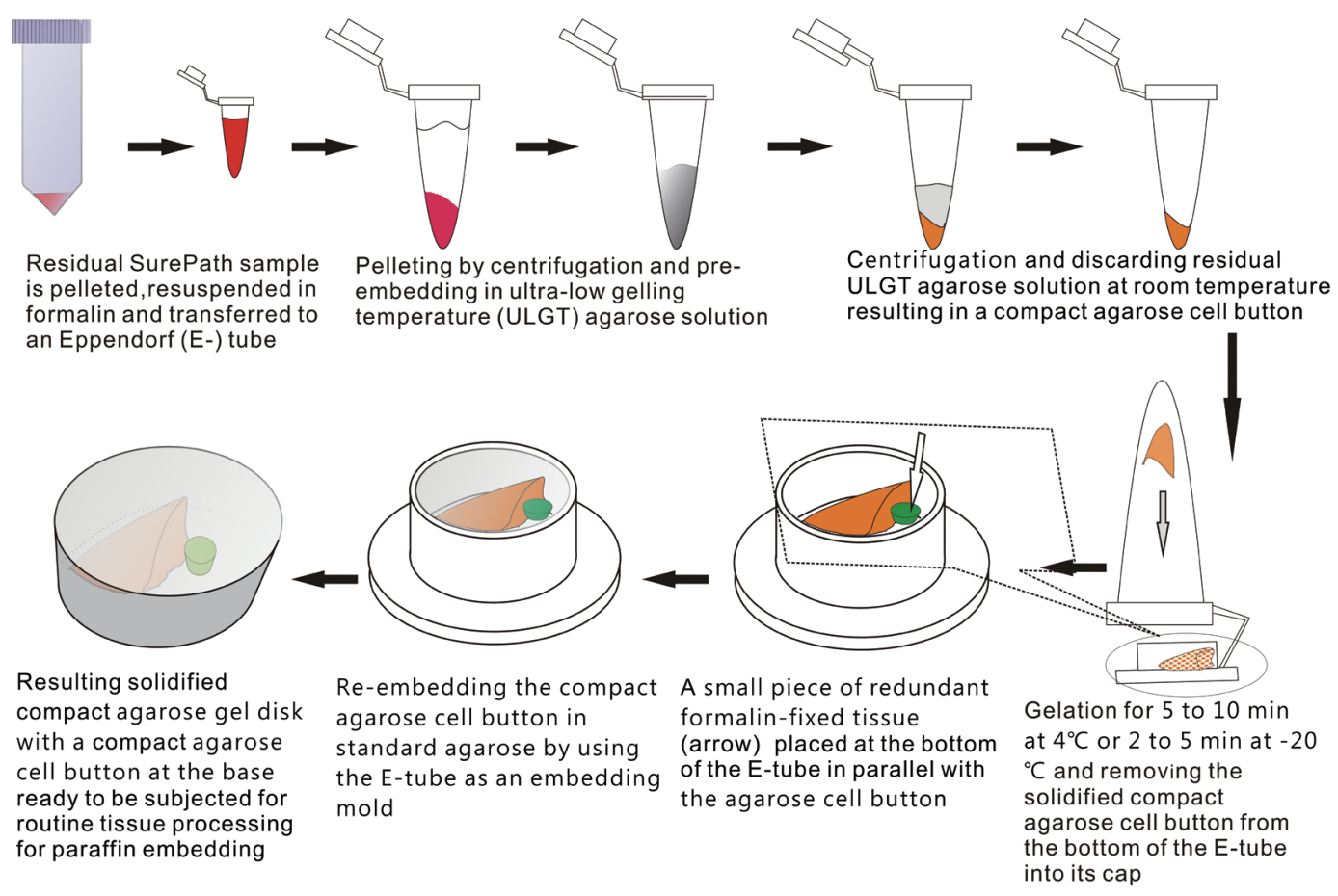

Fig. 1. Schematic flow chart of the protocol for preparation of compact agarose cell blocks from the residues of liquid-based cytology samples. 

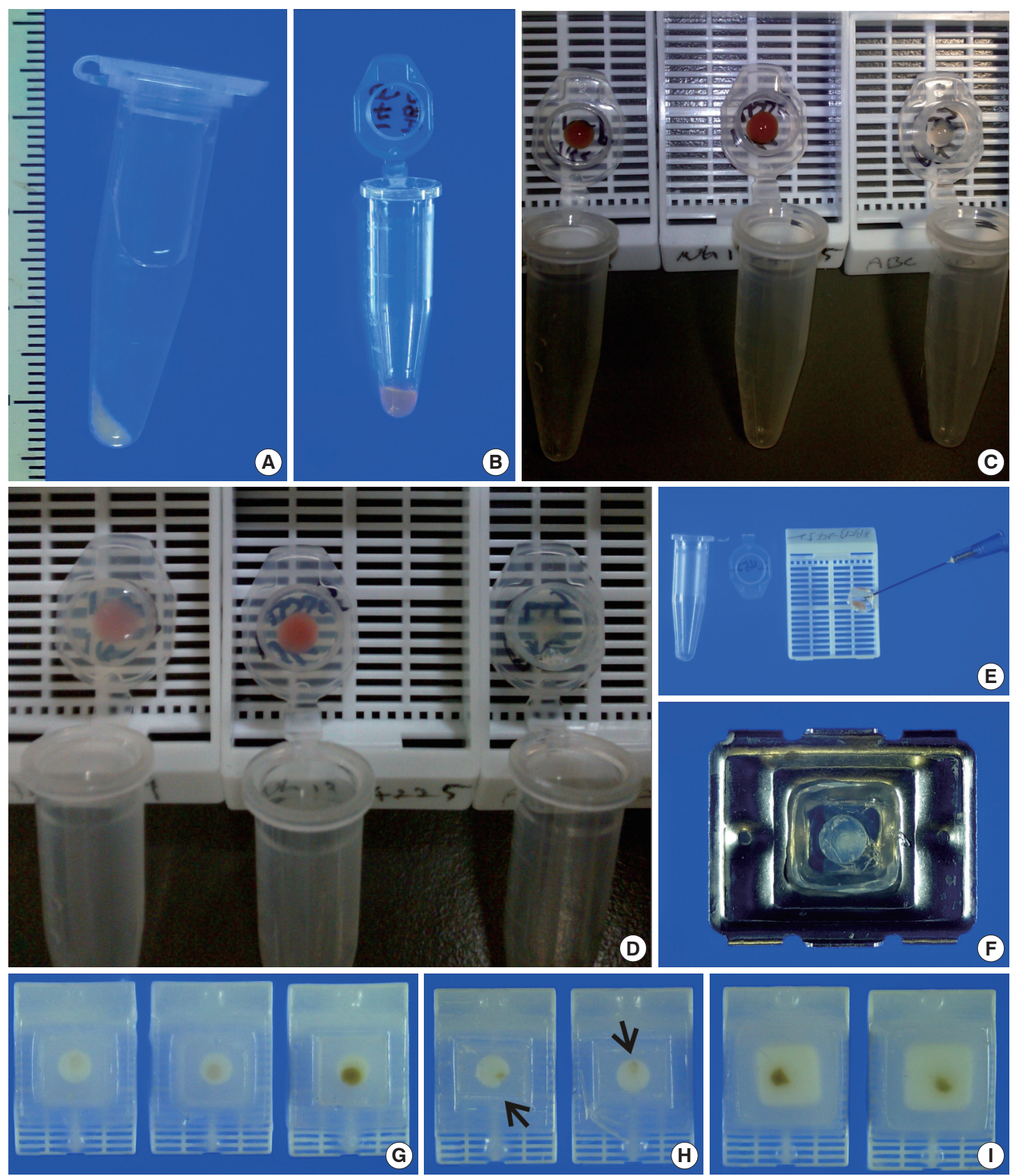

Fig. 2. Agarose cell block preparation. The residue of a SurePath sample is placed in Eppendorf reaction tubes and fixed in formalin (A). Then, the material is pelleted and resuspended with a minimal volume of $3 \%(\mathrm{w} / \mathrm{v})$ ultra-low gelling temperature agarose solution at room temperature and the resulting agarose cell suspension is allowed to gelate in the refrigerator at $4^{\circ} \mathrm{C}(\mathrm{B})$. Each of the solidified agarose cell buttons is transferred into the cap of the tube (C). Then, the cap with an agarose cell button at the bottom is filled with $3 \%$ standard agarose solution (D). The resulting agarose gel disk is removed from the cap with the aid of a 23-gauge needle (E) and then subjected to tissue processing for paraffin embedding. When the agarose gel disk is fractured during this step, it is carefully reconstructed and put in a tissue embedding mold and re-embedded in additional 3\% standard agarose solution (F). The agarose cell block is trimmed to expose the agarose cell button (G). If a small piece of redundant formalin-fixed tissue (arrows) is embedded in advance in parallel with the cell button, it can be effectively used as a visible marker indicating the optimal cutting level of the cell block $(H)$. Reconstructed gel disks are processed in the same way and embedded in paraffin blocks (I).

Depending on the size of the cell pellet or cellularity of the corresponding SurePath smear, the cell pellet was resuspended with 50 to $100 \mu \mathrm{L}$ ULGT agarose solution (Fig. 2B). Following re-centrifugation of the suspension on a table-top centrifuge at 
15,000 rpm for 30 seconds, the supernatant ULGT agarose solution was carefully discarded by pipetting. Finally, the resulting compact agarose cell button was allowed to solidify for 5 to 10 minutes at $4^{\circ} \mathrm{C}$ or 2 to 5 minutes at $-20^{\circ} \mathrm{C}$.

\section{Preparation of compact agarose cell blocks}

The solidified compact agarose cell button was removed into the cap of an Eppendorf reaction tube by tapping upside down on a hard surface or manually with a metal ear-pick (Fig. 2C). Then, the cap of the Eppendorf reaction tube was filled with standard agarose solution so that the agarose cell button was embedded at the base of the standard agarose gel (Fig. 2D). When the initial agarose cell button was nearly transparent, it was marked in advance with a tissue marking dye that could be used to indicate the optimal cutting level of the cell block. Alternatively, a small piece of redundant formalin-fixed tissue was embedded in parallel with the agarose cell button. Following solidification of the standard agarose gel at room temperature for 1 to 2 minutes, the resulting agarose gel disk with an agarose cell button at the base was carefully removed from the cap of the tube using a 22-gauge needle (Fig. 2E). When the agarose gel disk was fractured during this step, it was carefully reconstruct- ed and re-embedded in standard agarose gel (Fig. 2F). The resulting agarose gel disk was placed in a tissue cassette without additional wrapping and then was subjected to routine tissue processing under standard conditions using an automated tissue processor machine and embedded in paraffin. Finally, the cell block was trimmed to expose the agarose cell button (Fig. 2GI), from which serial 3 to 5 sections were cut at $4-\mu \mathrm{m}$ thickness and mounted on a slide for hematoxylin and eosin (H\&E) staining.

\section{Construction of cell block microarray for high throughput immunocytochemistry}

To save time and resources in examining the applicability of the agarose cell blocks to adjuvant immunocytochemistry, the cores of paraffin-embedded agarose cell buttons in the agarose cell blocks were represented in a CMA. ${ }^{16}$ In order to incorporate the entire cases into a single CMA, we used a self-made manual microarray kit and a homemade recipient block as described previously (Fig. 3). ${ }^{17,18}$ Tissue cores from redundant FFPET were also arrayed in the same CMA to be used as macroscopic orientation markers of the CMA sections. Serial sections were cut from the CMA and routinely processed for H\&E and immunostaining. An automated slide stainer (Ventana BenchMark XT,
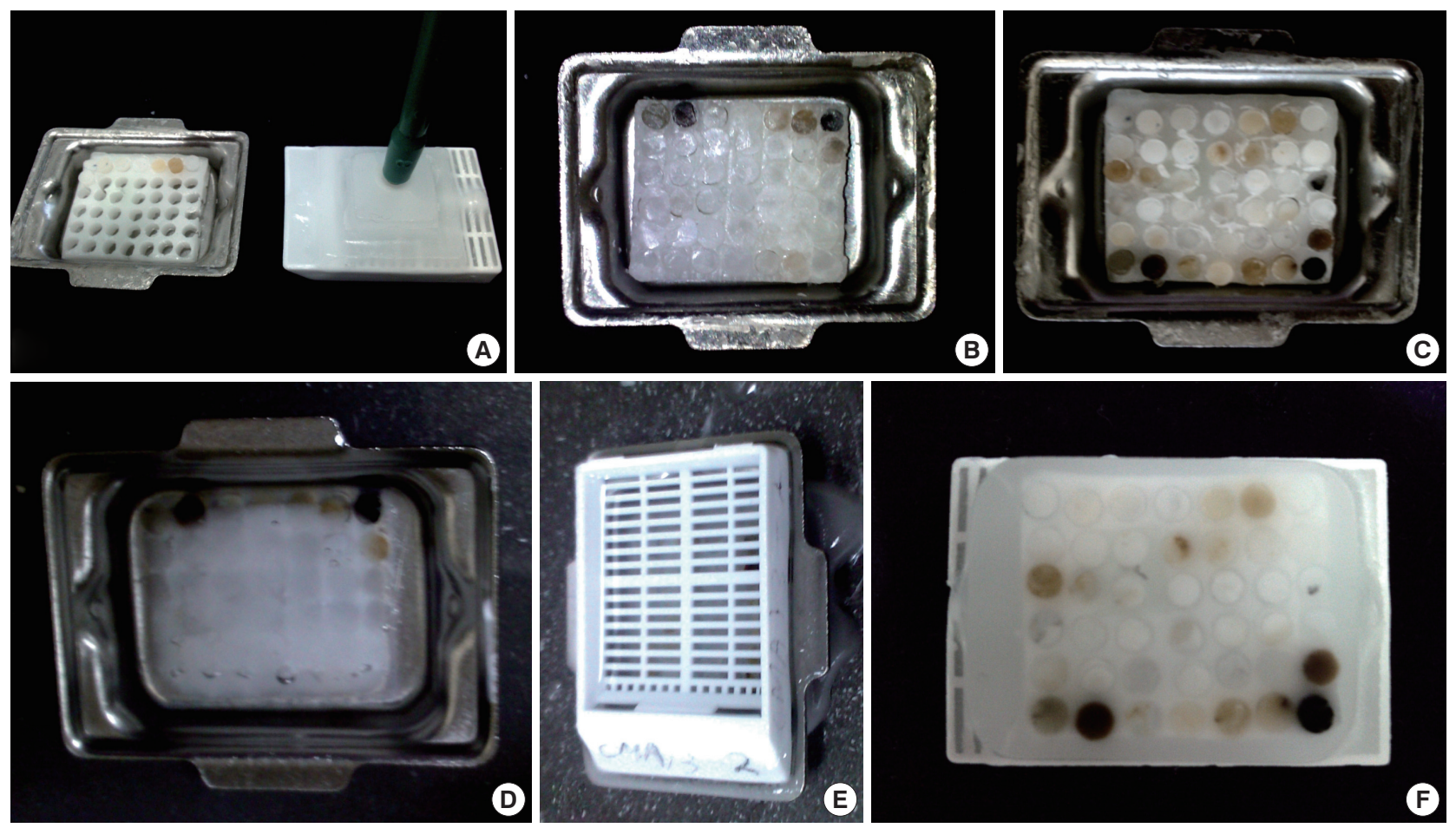

Fig. 3. Construction of a cell block microarray (CMA) for high-throughput immunocytochemistry of cell blocks. A 3-mm tissue punch is used to extract cores of agarose cell buttons from the agarose cell blocks and implant them in a ready-to-use homemade recipient agarose paraffin block (A, B). The CMA is completely melted on a heat plate to facilitate complete integration of cell block cores into the recipient agarose paraffin block (C, D). Finally, the CMA is re-embedded in paraffin and trimmed to expose the cell block cores (E, F). 
Ventana Medical Systems Inc., Tucson, AZ, USA) and the Ventana OptiView DAB detection kit were used to analyze expres-

Table 1. Sources and dilutions of antibodies used for immunocytochemistry of the cell block microarray

\begin{tabular}{lll}
\hline Target & \multicolumn{1}{c}{ Source } & Dilution \\
\hline Cytokeratin 19 & Dako & $1: 200$ \\
Galectin-3 & Novocastra & $1: 500$ \\
Thyroid transcription factor-1 & NeoMarkers & $1: 1,500$ \\
Thyroglobulin & NeoMarkers & $1: 1,500$ \\
Parathyroid hormone & NeoMarkers & $1: 400$ \\
CD56 & Novocastra & $1: 400$ \\
HBME1 & Cell Marque & $1: 400$ \\
D2-40 & Dako & $1: 300$ \\
Wilms' tumor-1 & Cell Marque & $1: 500$ \\
Calretinin & Chemicon & $1: 1,800$ \\
Leukocyte common antigen (CD45) & Dako & $1: 2,000$ \\
CD20 & Pharmingen & $1: 100$ \\
CD3 & Dako & $1: 100$ \\
Terminal deoxynucleotidyl transferase & Cell Marque & $1: 400$ \\
PAX5 & Cell Marque & $1: 400$ \\
\hline
\end{tabular}

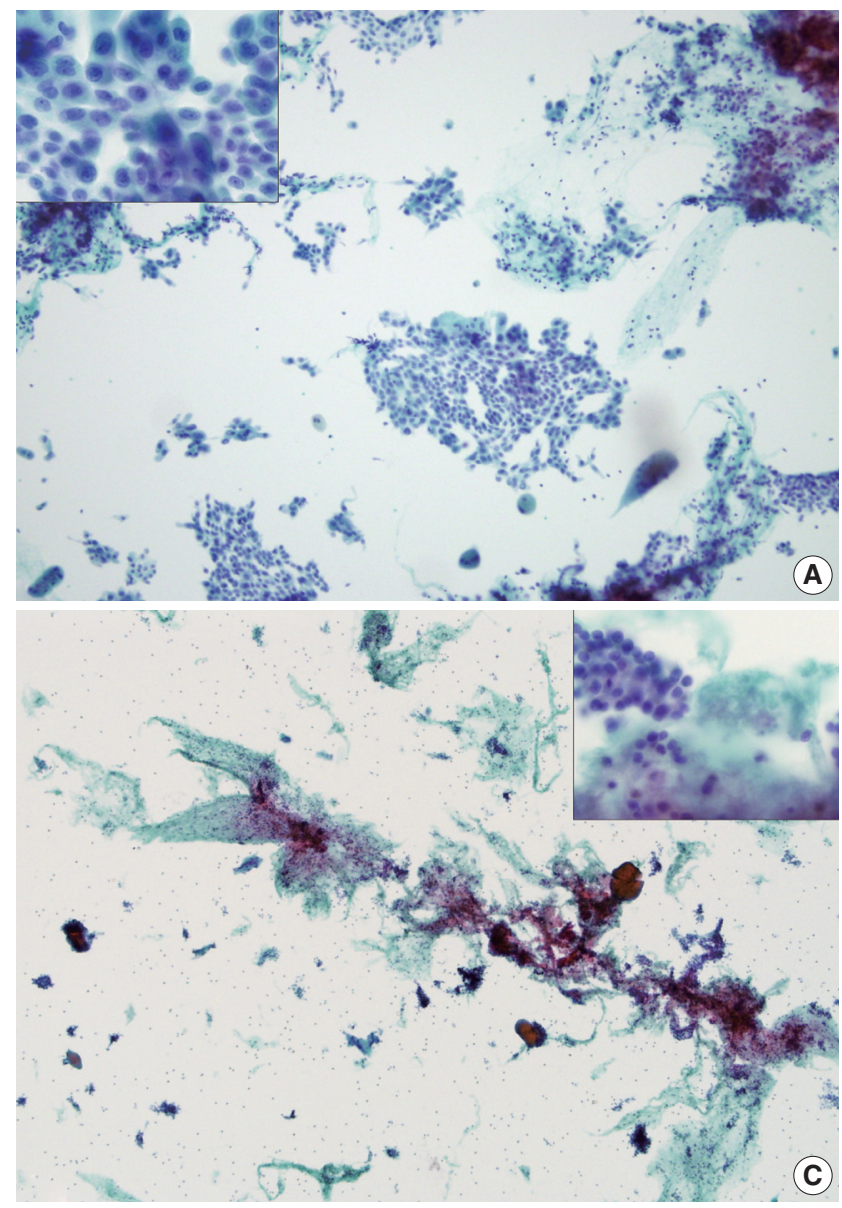

sion of markers (Table 1) using the same antibodies and protocols standardized for immunostaining of FFPET sections. A digital slide scanner (VM600, Motic, Xiamen, China) was used to acquire the entire image of the $\mathrm{H} \& \mathrm{E}$ and immunostained CMA sections.

\section{RESULTS}

\section{Compact agarose cell blocks}

By using ULGT agarose solution as a resuspending medium, the residual diagnostic materials in the residual SurePath sample was easily and entirely incorporated into a compact agarose cell button which measured 3 to $5 \mathrm{~mm}$ in diameter. By using the cap of an Eppendorf reaction tube as an embedding mold and the standard agarose as a pre-embedding medium, the compact agarose cell button was easily integrated at the base of an agarose gel disk, which was easy to manipulate for further pro-

Fig. 4. Representative SurePath smears and corresponding agarose cell blocks of thyroid fine needle aspirations. High cellularity in a SurePath smear of papillary thyroid carcinoma (A) correlates well with that of the agarose cell block section (B). Low cellularity in a SurePath smear of subacute granulomatous thyroiditis $(C)$ correlates well with that of the agarose cell block section (D). Insets depict high power views. 
cedures for tissue processing and paraffin embedding. Following the routine 12- to 13-hour tissue processing, all of the agarose gel disks were well impregnated with paraffin and retained their original size and shape. With the aid of FFPET embedded in parallel or a marking dye applied in advance to the agarose cell buttons, it was not difficult for the histotechnologists to determine the optimal cutting level of the cell blocks. Although a thin layer of nearly transparent agarose gel was present in the H\&E-stained sections, it did not obscure the cytologic and architectural features because it was retained outside the cells or

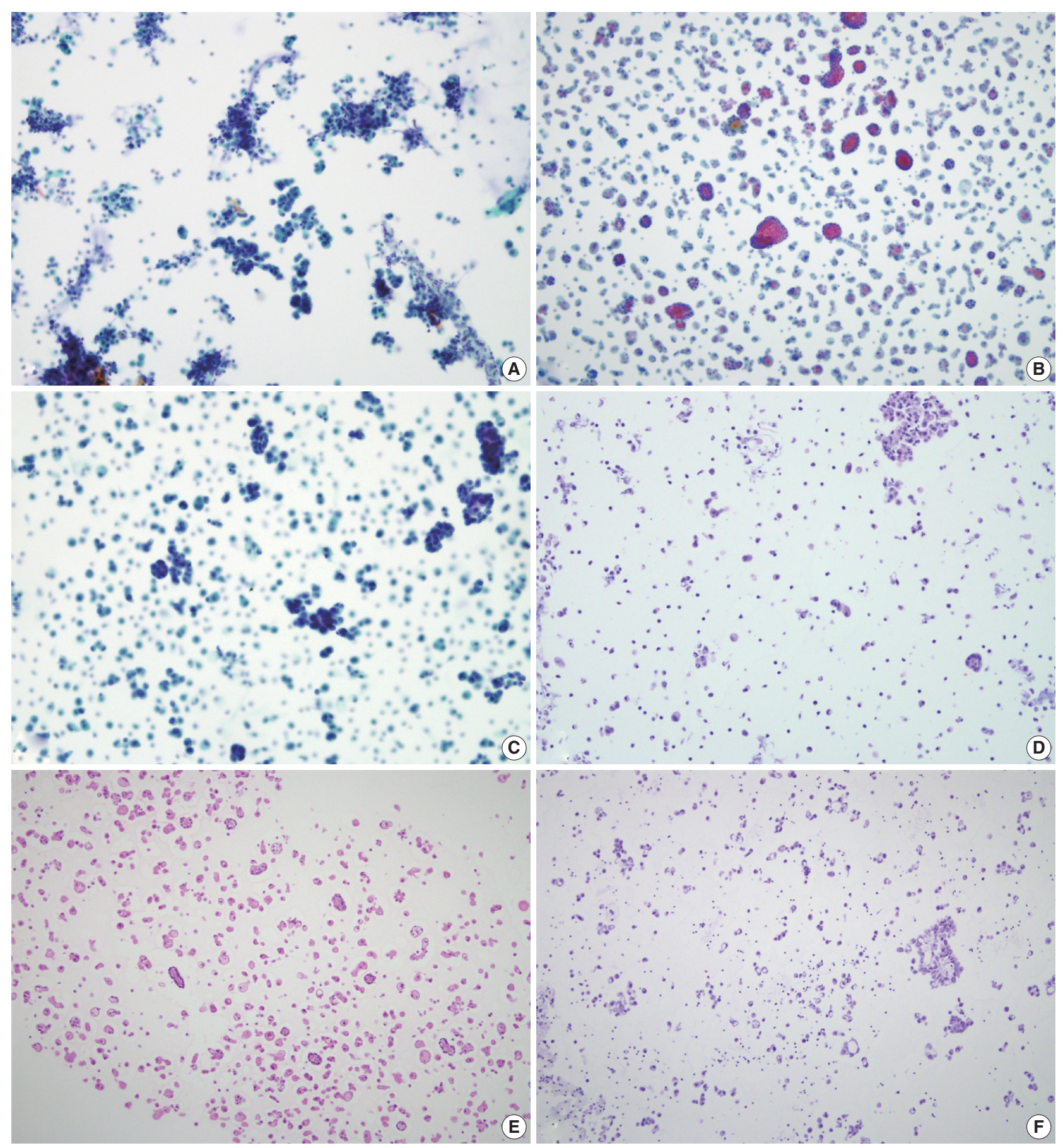

Fig. 5. SurePath smears and corresponding agarose cell blocks of serous effusions. The cellularities in SurePath smears of serous effusions with reactive mesothelial proliferation $(A)$, malignant mesothelioma $(B)$, and metastatic adenocarcinoma $(C)$ correlate well with those of corresponding agarose cell block sections (D-F), respectively. 
tissue fragments. The cytomorphologic features of the cell block sections were supportive for the original diagnosis of the corresponding SurePath smears (Figs. 4, 5).

\section{Construction of cell block microarray for high-throughput immunocytochemistry}

The cellularity yield of each cytology spot on the CMA section correlated well with that of the corresponding section of the donor agarose cell blocks (Fig 6A). With the entirety of the diagnostic material concentrated on a viewing cytology spot of each cell block, it was possible to minimize differences in cellu-

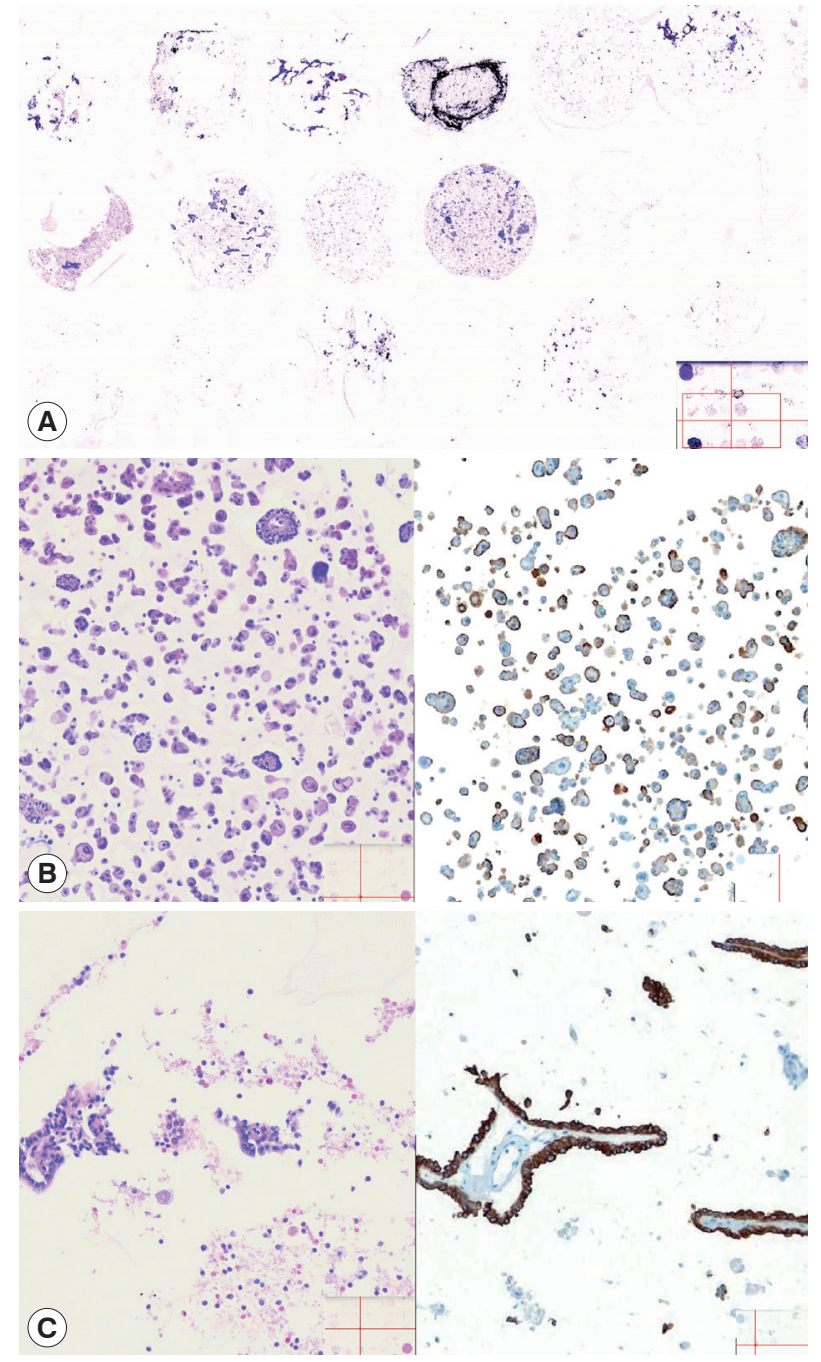

Fig. 6. Representative cytology spots on a section of cell block microarray. Depending on the cellularities of corresponding SurePath smears, the cytology spots on the cell block microarray showed various cellularities (A, H\&E). The cytoarchitectural and immunocytochemical features of malignant serous effusion ( $B, H \& E$ [left] and D2-40 [right]) and atypical thyroid fine needle aspirate (C, H\&E [left] and cytokeratin 19 [right]) are supportive for more specific and more confidential diagnosis, respectively. larity yield through serial sections of the CMA cut for a series of immunocytochemistry using panels of diagnostic markers (Table 2). Immunocytochemical analyses of the cytology spots on the CMA provided additional information supportive for the diagnosis of cytologically difficult cases (Figs. 6B, 6C, 7).

\section{DISCUSSION}

Although smears of alcohol-fixed liquid-based or cytocentrifuged preparations of cytology samples can be used for complementary immunocytochemistry, the quality of the immunostains from smear preparations cannot be always identical to that of formalin-fixed paraffin embedded cell block sections. ${ }^{4,5}$ This is because the cell block provides the most reliable form of sample preparation that produces results identical to that of FFPET. Furthermore, multiple sections can be cut from the cell blocks that can be effectively used when definitive differential diagnosis should be rendered only based on appropriate histologic, immunocytochemical or cytochemical findings. ${ }^{19}$

In order to be used in routine ancillary tests such as immunocytochemistry, a cell block should retain a yield of cellularity sufficient enough for ancillary tests. More often than not, however, H\&E-stained and/or immunostained sections of conventionally prepared cell blocks fail to provide additional clues for differential diagnosis even though the corresponding smear preparations of the cytology sample retain sufficient cellularities. This is because the informative residual materials remained after routine smear preparations cannot always be incorporated entirely into the cell blocks due to technical difficulity. ${ }^{3,7}$ This is because considerable loss or dilution of diagnostically important materials can occur during the preparation of cell blocks using the conventional simple sedimentation method. This problem mainly occurs when cell pellets are manually removed from the tubes, wrapped in lens paper and transferred into tissue cassettes before subjected to routine tissue processing for paraffinization. ${ }^{20}$ Bloody samples should be another major cause of scarce cellularity in cell block sections because the peripheral blood further dilutes the cells or tissue fragments of interest.

To overcome the loss of material during cell block preparation, various supporting media such as bacterial agar, egg albumin, and plasma-thrombin have been used. ${ }^{21}$ Among these, preparation of agarose cell blocks by using small volumes of agarose solution as pre-embedding media can be a simple and cost-effective method because cell buttons pre-embedded in standard agarose gel are easy to handle during the procedures for paraffin embedding. ${ }^{8-10}$ The advantages of the agarose cell 
Table 2. Cytologic samples incorporated into cell block microarray and result of immunocytochemistry

\begin{tabular}{|c|c|c|c|c|}
\hline Samples & Site & Diagnosis of smears & Supportive immunocytochemistry of cell block* & Diagnosis based on ICC \\
\hline $\begin{array}{l}\text { LBC_FNAs } \\
\text { (SurePath) }\end{array}$ & Thyroid & $\begin{array}{l}\text { Papillary carcinoma }(n=8) \\
\text { Suspicious for papillary carcinoma } \\
\quad(n=2) \\
\text { Nodular hyperplasia }(n=12) \\
\text { Atypia }(n=4) \\
\text { Atypia }(n=1) \\
\text { Benign Hurthle cell proliferation }(n=2) \\
\text { Chronic lymphocytic thyroiditis }(n=2) \\
\text { Lymphoid malignancy }(n=2)\end{array}$ & $\begin{array}{l}\text { TG+, TTF1+, CK19+, galectin 3+, CD56-, HBME1+, PTH- } \\
\text { TG+, TTF1+, CK19+, galectin 3+, CD56-, HBME1+, PTH- } \\
\text { TG+, TTF1+, CK19-, galectin 3-, CD56+, HBME1-, PTH- } \\
\text { TG+, TTF1+, CK19-, galectin 3-, CD56+, HBME1-, PTH- } \\
\text { TG-, TTF1-, CK19+, galectin 3-, CD56-, HBME1-, PTH+ } \\
\text { TG+, TTF1+, CK19-, galectin 3-, CD56+, HBME1-, PTH- } \\
\text { N/A due to scanty cellularity } \\
\text { CD45-, CD20-, CD3-, TdT+, PAX5+, CD56- } \\
\text { CD45+, CD20+, CD3-, TdT-, PAX5+, CD56-- }\end{array}$ & $\begin{array}{l}\text { odular hyperplasia } \\
\text { odular hyperplasia } \\
\text { arathyroid lesion } \\
\text { enign Hurthle cell lesion } \\
\text { /A } \\
\text {-lymphoblastic lymphoma } \\
\text { arge B-cell lymphoma }\end{array}$ \\
\hline $\begin{array}{l}\text { LBC_serous } \\
\text { effusions } \\
\text { (SurePath) }\end{array}$ & $\begin{array}{l}\text { Ascitic fluid } \\
\text { Pleural } \\
\text { effusion }\end{array}$ & $\begin{array}{l}\text { Lymphoid malignancy }(n=1) \\
\text { Adenocarcinoma }(n=1) \\
\text { Adenocarcinoma }(n=1) \\
\text { Favor malignant mesothelioma }(n=1) \\
\text { Negative for malignancy }(n=1)\end{array}$ & $\begin{array}{l}\text { CD45+, CD20-, CD3-, TdT+, PAX5+, CD56- } \\
\text { CK7+, CK19+, calretinin-, D2-40, WT1+, CD56-, TTF1- } \\
\text { CK7+, CK19+, calretinin-, D2-40-, HBME1-, WT1-, TTF1+ } \\
\text { CK7+, CK19+, calretinin+, D2-40+, HBME1+, WT1+, TTF1- } \\
\text { N/A }\end{array}$ & $\begin{array}{l}\text { B-lymphoblastic lymphoma } \\
\text { Ovarian serous carcinoma } \\
\text { Adenocarcinoma of lung } \\
\text { primary } \\
\text { Malignant mesothelioma } \\
\text { N/A }\end{array}$ \\
\hline
\end{tabular}

ICC, immunocytochemistry; LBC, liquid-based cytology; FNA, fine needle aspiration; cytokeratin; TG, thyroglobulin; TTF1, thyroid transcription factor-1; CK, cytokeratin; PTH, parathyroid hormone; N/A, not applicable; TdT, terminal deoxynucleotidyl transferase; WT1, Wilms' tumor-1.

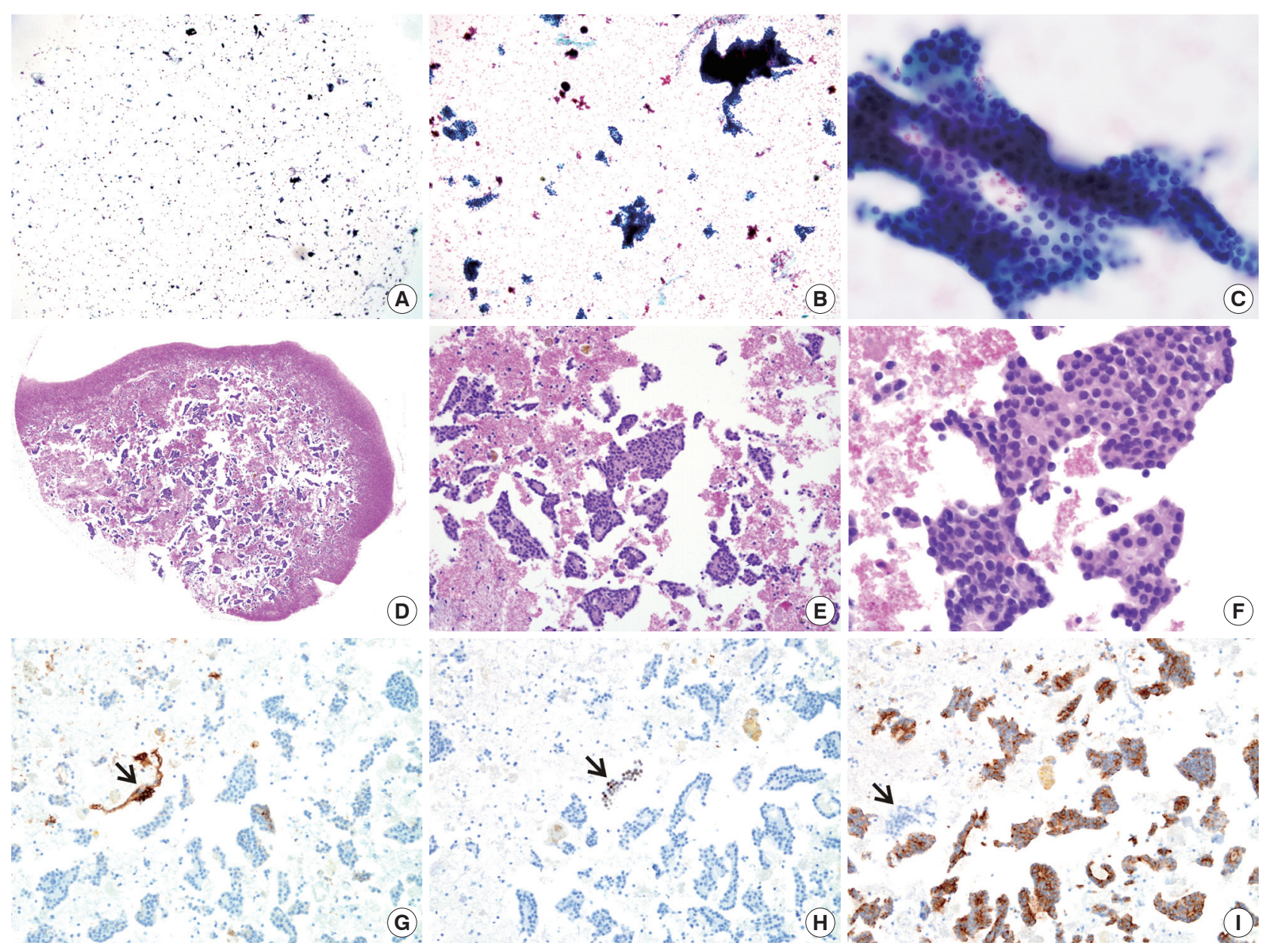

Fig. 7. SurePath smear and agarose cell block from parathyroid lesion. The SurePath sample is allegedly from an intrathyroidal nodule. The smear (A-C) with cohesive clusters and solid sheets of relatively monomorphic epithelial cells was interpreted as "atypia of undetermined significance." The diagnosis is confirmed by cytoarchitectural examination (D-F) and immunocytochemical analysis (G, thyroglobulin; $H$, thyroid transcription factor-1; I, parathyroid hormone; arrows indicating positive and negative controls) of cell block sections. 
block technique has been already confirmed. ${ }^{22-24}$ However, the major drawback of this technique is that the agarose solution should be kept in a temperature not lower than the gelling temperature of agarose solution to prevent premature solidification of the agarose solution while cell pellets are resuspended. If this inadvertently occurs, the cells or tissue fragments within the cell pellets will not be evenly distributed throughout the agarose cell button. Although the agarose solution can be kept in a preheated heat block in an oven set at $60^{\circ} \mathrm{C}$ during the resuspending step, it could be technically difficult for routine cell block preparation in daily practice.

Mansy ${ }^{11}$ took the advantage of the agarose cell block technique using low melting temperature (LGT) agarose to make agarose cell blocks from urine cytology samples. In several preceding trials with this method, however, we have found that the usual LGT agarose solution should also be kept at a temperature above room temperature (usually $>30^{\circ} \mathrm{C}$ ) to prevent premature solidification. Otherwise, it was not possible to have diagnostic cells or tissue fragments evenly distributed throughout different levels. This was especially the case when we tried to resuspend cell pellets with small volumes of agarose solution to make small agarose cell button as compact as possible. To overcome this problem, we modified the method for agarose cell block preparation using two types of agarose that become gels at different temperatures: ULGT agarose is for preparation of agarose cell buttons and standard agarose is for re-embedding in agarose gel disks. Because the ULGT agarose solution does not solidify at room temperature, it can be effectively used to resuspend the formalin-fixed cell pellet from the LBC sample that remains after smear preparation. In addition, the suspension can be centrifuged again at room temperature in order to get more concentrated agarose cell buttons. We presume that this modified technique enables the diagnostic material in the residual LBC samples to be transferred as entirely as possible into small agarose cell buttons that are as compact as possible.

In the preliminary experiment to modify the agarose cell block technique, we found that the gelation property of the agarose solution significantly deteriorates with time when the agarose solution was kept in the oven at $60^{\circ} \mathrm{C}$ for more than 1 month. Furthermore, the agarose solution kept in the oven more than 2 months changed to brownish yellow color and the gelation property was completely lost. To prevent this problem, we aliquoted the agarose solutions into one time use aliquots and stored them at $4^{\circ} \mathrm{C}$ until they were re-melted using a microwave. Because only a small amount of agarose is needed for agarose cell block preparations, there was no significant increase in cost for agarose cell block preparation. Furthermore, because solidified agarose buttons and agarose gel disks are easier to manipulate compared to wrapping the cell pellet with lens paper, the time and work load do not substantially increase compared to conventional simple sedimentation method, although we did not analyze this observation statistically.

In conclusion, we illustrated a modified agarose cell block technique to obtain compact agarose cell blocks that prevents significant loss of diagnostic cells or tissue during cell block preparation. This modified technique can be widely applied in daily cytopathology practice, especially when the cellularity of the cytologic sample is expected to be low.

\section{Conflicts of Interest}

No potential conflict of interest relevant to this article was reported.

\section{Acknowledgments}

This work was supported by Inha University Research Grant.

The authors wish to thank Yu Hwan Lim, Kyung Hwan Jang, Yong Hoon Lee, Young Min Lee, and Seok Joon Hong in the histology lab for their technical support and advice in the construction of the TMA blocks and Kyung Shin Kim and Eun Sook Kim in the immunopathology section for their excellent immunohistochemistry.

\section{REFERENCES}

1. Khan S, Omar T, Michelow P. Effectiveness of the cell block technique in diagnostic cytopathology. J Cytol 2012; 29: 177-82.

2. Ikeda K, Tate G, Suzuki T, Mitsuya T. Comparison of immunocytochemical sensitivity between formalin-fixed and alcohol-fixed specimens reveals the diagnostic value of alcohol-fixed cytocentrifuged preparations in malignant effusion cytology. Am J Clin Pathol 2011; 136: 934-42.

3. Fetsch PA, Simsir A, Brosky K, Abati A. Comparison of three commonly used cytologic preparations in effusion immunocytochemistry. Diagn Cytopathol 2002; 26: 61-6.

4. Udasimath S, Arakeril SU, Karigowdar MH, Yelikar BR. The role of the cell block method in the diagnosis of malignant ascitic fluid effusions. J Clin Diagn Res 2012; 6: 1280-3.

5. Fowler LJ, Lachar WA. Application of immunohistochemistry to cytology. Arch Pathol Lab Med 2008; 132: 373-83.

6. Zito FA, Gadaleta CD, Salvatore C, et al. A modified cell block technique for fine needle aspiration cytology. Acta Cytol 1995; 39: 93-9.

7. Hecht SA, McCormack M. Comparison of three cell block techniques 
for detection of low frequency abnormal cells. Pathol Lab Med Int 2013; 5: 1-7.

8. Olson NJ, Gogel HK, Williams WL, Mettler FA Jr. Processing of aspiration cytology samples. An alternative method. Acta Cytol 1986; 30: 409-12.

9. Kerstens HM, Robben JC, Poddighe PJ, et al. AgarCyto: a novel cellprocessing method for multiple molecular diagnostic analyses of the uterine cervix. J Histochem Cytochem 2000; 48: 709-18.

10. Mayall F, Chang B, Darlington A. A review of 50 consecutive cytology cell block preparations in a large general hospital. J Clin Pathol 1997; 50: 985-90.

11. Mansy SS. Agarose cell block: innovated technique for the processing of urine cytology for electron microscopy examination. Ultrastruct Pathol 2004; 28: 15-21.

12. Schieven LW, Smedts F, Hopman AH, van der Wijk J, Nijman RJ, de Jong IJ. Fine needle aspiration using improved agar microbiopsy is highly concordant with renal mass final diagnosis and subclassification. J Urol 2009; 182: 2590-3.

13. Wagner DG, Russell DK, Benson JM, Schneider AE, Hoda RS, Bonfiglio TA. Cellient automated cell block versus traditional cell block preparation: a comparison of morphologic features and immunohistochemical staining. Diagn Cytopathol 2011; 39: 730-6.

14. Zhao J, Lin DL, Zhai LH, Wang JG. Evaluation of ultrasound-processed rapid cell blocks in the cytopathologic diagnosis of cavity fluids. Acta Cytol 2014; 58: 182-91.

15. Crapanzano JP, Heymann JJ, Monaco S, Nassar A, Saqi A. The state of cell block variation and satisfaction in the era of molecular diagnostics and personalized medicine. Cytojournal 2014; 11: 7.
16. Pu RT, Giordano TJ, Michael CW. Utility of cytology microarray constructed from effusion cell blocks for immunomarker validation. Cancer 2008; 114: 300-6.

17. Choi CH, Kim KH, Song JY, et al. Construction of high-density tissue microarrays at low cost by using self-made manual microarray kits and recipient paraffin blocks. Korean J Pathol 2012; 46: 562-8.

18. Kim KH, Choi SJ, Choi YI, et al. In-house manual construction of high-density and high-quality tissue microarrays by using homemade recipient agarose-paraffin blocks. Korean J Pathol 2013; 47: 238-44.

19. Liu K, Dodge R, Glasgow BJ, Layfield LJ. Fine-needle aspiration: comparison of smear, cytospin, and cell block preparations in diagnostic and cost effectiveness. Diagn Cytopathol 1998; 19: 70-4.

20. Hecht SA, McCormack M. Comparison of three cell block techniques for detection of low frequency abnormal cells. Pathol Lab Med Int 2013; 5: $1-7$.

21. Bales CE, Durfee GR. Cytological technique, part 1. In: Koss LG, Melamed MR, eds. Koss' diagnostic cytology and its histopathologic bases. 4th ed. Philadelphia: Lippincott JB, 1992; 1451-74.

22. Zanoni DS, Grandi F, Cagnini DQ, Bosco SM, Rocha NS. Agarose cell block technique as a complementary method in the diagnosis of fungal osteomyelitis in a dog. Open Vet J 2012; 2: 19-22.

23. Zanoni DS, Grandi F, Rocha NS. Use of the agarose cell block technique in veterinary diagnostic cytopathology: an "old and forgotten" method. Vet Clin Pathol 2012; 41: 307-8.

24. Mansy SS, Abbas MA, Yehia HA, Abdelrazik SM, Ghanem LY, Amin TM. Value of the innovated technique agarose cell block in improving the sensitivity of urine cytology in cases of bladder carcinoma. Ultrastruct Pathol 2006; 30: 379-85. 